\section{Fight on two fronts}

\author{
G. E. R. Lloyd
}

Jewish Thought and Scientific Discovery in Early Modern Europe. By David B. Ruderman. Yale University Press: 1995. Pp. 392. \$30, £20.

SPECULATION about the causes of the socalled scientific revolution continues to pour from the presses and to fill radio and television programmes. But how far is this just idle curiosity? There are fundamental problems with both what has to be explained and how to explain it. Even in the political sphere, 'revolutions' are hard to define and delimit. The import of the term into the history of science may have been pedagogically convenient and it certainly had a role in the claims made for the subject as an academic discipline. But nowadays those who study the complex changes in astronomy, cosmology, optics, anatomy, physiology, pathology and so on in the sixteenth and seventeenth centuries generally agree that to apply the term 'revolution' to cover all of these, or even a determinate subset of them (as in the 'Copernican revolution'), is more misleading than helpful. First, it suggests greater uniformity between and within these fields than we are entitled to assume; and second, it biases discussion towards a focus on discontinuities rather than on the often equally important continuities in the data.

As to which explanatory factors are relevant to the problems once they have been redefined, there too controversy rages. Time was when histories of science were liberally supplied with maps indicating the place of birth of notable figures, although why other men and women of Woolsthorpe, say, did not turn into Newtons was not a problem that received much attention. Is the fact that some such figure was a Protestant or a Roman Catholic relevant? That too has been popular. But most generalizations fall foul of a mass of counterevidence, for example concerning the Protestants or the Catholics who simply failed to share the views and attitudes deemed important for promoting or inhibiting certain types of study.

This latest study is a mine of information about the ideas, lives and work of particular Jews. Yet despite what the ambiguous title might suggest, this is less a history of the scientific discoveries made by Jews in the early modern period than of Jews' changing attitudes towards such discoveries, or rather towards the study of nature more generally; that is, not so much a study of Jewish contributions to science, which are recognized to have been, in general, inconsequential in the early modern period, as one of the internal polemics within Jewish communities about what to make of science in the sense of knowledge of the natural world.

Both in time and space the range of the study is daunting. In an introductory chapter, David Ruderman discusses the mediaeval period (roughly the tenth to the fifteenth centuries), although this does not allow much room to comment on such important figures as Maimonides and Gersonides. The core of the book is devoted to three main groups of Jews, those exiled from Portugal and Spain, and those active in eastern Europe and in Italy, from the sixteenth to the early eighteenth centuries.

One recurrent theme is the disputes within the Jewish communities about what to make of the study of nature. Just as Maimonides and Nahmonides took up opposing positions on this in the twelfth and thirteenth centuries, so too were there often bitter controversies, between Moses Isserles and Solomon Luria, and the Maharal of Prague and de' Rossi in the sixteenth century, and between Leone Modena and Joseph ben Judah Hamiz, and between Samson Morpurgo and Solomon Basilea in the seventeenth. In some cases, Jewish defence of the study of nature takes a similar form to some Christian ones, for example in the use of arguments that drove a wedge between science and religion by suggesting that science could claim to deliver no more than the hypothetical and so was no threat to the certainties of faith.

But where Christian apologists fought on one front - with other Christians many Jews had to fight on two, first with their co-religionists, and then a different

\section{New in paperback}

Weather Facts by Dick File. OUP, £7.99. A forecaster at the UK Meteorological Office provides readable explanations of everything from the birth of the atmosphere through to the greenhouse effect.

Trilobites by Riccardo Levi-Setti (2nd edition). University of Chicago Press, $\$ 24.95, £ 19.95$. The author, an amateur trilobite collector, combines authoritative text with a vivid black-and-white photographic atlas of these "butterflies of the sea'.

Sedimentary Rocks in the Field by Maurice E, Tucker (2nd edn). Wiley, $£ 10.99$. A useful pocket-sized guide, with many tables, diagrams, photographs and checklists, covering field techniques, sedimentary rock types, textures and structures, fossils and facies analysis.

Dictionary of Environmental Science and Technology by Andrew Porteous (2nd edn). Wiley, £12.99. In-depth entries by a professor of environmental engineering are accompanied by diagrams and tables, a list of relevant UK addresses and a guide to further reading. battle to defend their positions in relation to the dominant, Christian, culture. The fact that for most of the period in question Jews were generally excluded from most universities must rank as one of the most important considerations in explaining the nature and limitations of direct Jewish involvement in scientific research. The chief exception, the University of Padua, tends to prove the rule. It did allow Jewish medical students from the early sixteenth century. Many of the author's leaders of Jewish opinion, who often combined the roles of physician and rabbi, graduated from this university: they include Joseph Delmedigo, Hamiz, Morpurgo, Tobias Cohen, David Nieto and Isaac Lampronti.

The main strength of this book lies in the careful study of the lives and writings of these and other figures. But many opportunities are missed. The author notices which texts were originally written in Hebrew, in Arabic, in Latin or in the vernacular. Yet his material cries out for further analysis of the differences that different potential audiences made, of the use of different modes of rhetoric in different contexts, as well as of the social positions, employment and access to patronage of the key figures. The reader is offered some insights into little known aspects of life in Cracow at the time of Copernicus and in Padua in Galileo's youth. But the actual scientific debates against which their work has to be judged are beyond Ruderman's brief.

G. E. R. Lloyd is at Darwin College, Cambridge CB3 9EU, UK.

Regional Advantage: Culture and Competition in Silicon Valley and Route 128 by Annalee Saxenian. Harvard University Press, \$14.95, £9.50. An account of the economic, organizational and technological evolution of California's foremost high-technology regions, based on more than a hundred interviews.

Mountain in the Clouds: A Search for the Wild Salmon by Bruce Brown. University of Washington Press, $\$ 12.95$. A thoughtful study of the decline of the wild Pacific salmon owing to human settlement, farming, timbering and commercial fishing.

State of the World 1996 by Lester R. Brown et al.. Earthscan, £12.95. A Worldwatch Institute report on progress towards a sustainable society.

The Psychology of Interrogations, Confessions and Testimony by Gisli Gudjonsson. Wiley, £15.99. Gudjonsson, an eminent forensic psychologist, "reveals the messy truth about interrogation and confession; his welcome and timely book should be required reading for all who strike public attitudes on crime and punishment", wrote Steve Blinkhorn in a review in Nature 362, 655 (1993). 